\title{
O iniciante e o iniciado: a tradição como ausência na obra de Raymond Carver
}

Gustavo Naves Franco ${ }^{1 *}$

${ }^{1}$ Universidade Federal do Estado do Rio de Janeiro, Rio de Janeiro/RJ - Brasil

\section{RESUMO}

O artigo propóe uma análise da obra do escritor estadunidense Raymond Carver (19381988), com ênfase na ausência de tradiçôes estéticas e sociais no pano de fundo de seu universo ficcional. A partir dos debates e polêmicas envolvendo a publicação de sua segunda coletânea de contos, hoje conhecida como Iniciantes, as diferentes perspectivas de Carver e de seu editor Gordon Lish na concepção do livro evidenciam modos distintos de relacionamento com a tradição literária. No primeiro caso, temos uma destituição de lastros socioculturais, tanto por parte do autor quanto de seus personagens, enquanto nos procedimentos pós-modernistas de Lish a relação com uma herança histórica é enfatizada através da ruptura e da fragmentação do texto. Surgem assim as figuras do "iniciante" (Carver) e do "iniciado" (Lish), que não apenas servem ao esclarecimento das diferenças entre ambos, como também oferecem uma tipologia à análise de índices temporais e históricos em textos de ficção.

Palavras-chave: Raymond Carver; Gordon Lish; historicidade; conto estadunidense; literatura estadunidense - sec. XX.

\section{The beginner and the initiated: tradition as absence in Raymond Carver's works}

\section{ABSTRACT}

The article analyzes the published work of North American writer Raymond Carver (19381988), with an emphasis on the absence of aesthetic and social traditions in the background of his fictional universe. It looks at the debates and disagreements between Carver and his editor Gordon Lish over his second collection of short stories—now known as Beginners — as

DOI: http://dx.doi.org/10.1590/2237-101X02104406

Artigo recebido em 28 de janeiro de 2019 e aceito para publicaçáo em 3 de setembro de 2019.

* Professor da Universidade Federal do Estado do Rio de Janeiro / Escola de Letras, Rio de Janeiro/RJ - Brasil. E-mail: gnavesfranco@gmail.com. ORCID: https://orcid.org/0000-0003-0218-8513 
an expression of different forms of dialogue with literary tradition. In Carver's writing there is a dearth of sociocultural references, both on the part of the author and his characters, while Lish emphasizes historical heritage through rupture and fragmentation of the text. This paper introduces the categories of the "beginner" (Carver) and the "initiated" (Lish), which serve not only to clarify the differences between both writers, but also to offer a typology for analyzing temporal and historical components of fictional texts.

Keywords: Raymond Carver; Gordon Lish; historicity; American short-story; $20^{\text {th }}$ century American literature.

\section{El iniciante y el iniciado: la tradición como ausencia en la obra de Raymond Carver}

\section{RESUMEN}

El artículo propone un análisis de la obra del escritor estadounidense Raymond Carver (1938-1988), con énfasis en la ausencia de tradiciones estéticas y sociales en el paño de fondo de su universo de ficción. A partir de debates y polémicas envolviendo la publicación de su segunda recopilación de escritos, hoy conocida como Iniciantes, las diferentes perspectivas de Carver y de su editor Gordon Lish en la concepción del libro evidencian modos distintos de relacionamientos con la tradición literaria. En el primer caso, tenemos una destitución de lastres socioculturales, tanto por parte del autor, como de sus personajes, mientras en los procedimientos posmodernistas de Lish, la relación con una herencia histórica es enfatizada a través de la ruptura y fragmentación del texto. Surgen así, las figuras del "iniciante" (Carver) y del "iniciado" (Lish), que no apenas sirven al esclarecimiento de las diferencias entre ambos, como también ofrece una tipología de análisis temporales e históricos en textos de ficción.

Palabras clave: Raymond Carver; Gordon Lish; historicidad; cuento estadounidense; literatura estadounidense; siglo XX.

\section{Apresentação}

" 8 de julho, 8 da manhã". Assim está datada uma carta que, em 1980, o escritor estadunidense Raymond Carver enviou a seu amigo e editor Gordon Lish. O detalhe do horário é significativo: ele confere dramaticidade a um texto redigido através de uma longa jornada noite adentro, tendo como único propósito dissuadir Lish de publicar a próxima coletânea 
de contos de Carver, ou ao menos de publicá-la na versão que o escritor recebera para análise e confirmaçãa. Hoje, sabemos que a reação de Carver não foi desproporcional (ou despropositada) diante das incisivas intervençóes que seus manuscritos sofreram entre o envio das versôes iniciais e a preparação do texto pelo editor. Porém, já no dia 10 de julho, tendo recebido a carta e telefonado a Carver, Lish conseguiu fazê-lo aceitar as mudanças propostas, contando também com o argumento de que Carver havia assinado um contrato autorizando previamente eventuais alteraçóes (CARVER, 2009a; SKLENICKA, 2009).

Nem por isso a referida carta deixou de ser um dos mais importantes documentos para pesquisadores da obra de Raymond Carver. As grandes diferenças entre as versôes de Carver e Lish para os contos tornaram-se conhecidas em 2008, com a publicação nos Estados Unidos de Beginners, a partir dos manuscritos recuperados dos arquivos de uma biblioteca da Universidade de Indiana. Logo em seguida, a publicação do livro no Brasil (Iniciantes, 2009) gerou também interesse, fazendo com que críticos e resenhistas conferissem uma atenção especial ao histórico da obra.

Porém, ainda que a obra de Carver tenha alcançado maior ressonância neste período, a oportunidade não chegou a ser aproveitada para um desenvolvimento substancial na análise de seus textos, ou na compreensão de suas relaçôes com fenômenos de maior escala da história literária do século XX. Diante disso, a proposta deste artigo é a de investigar o embate, as negociaçôes, as dissonâncias e os acordos envolvendo a primeira publicação do livro, não apenas como curiosidade histórica ou material para a polêmica especializada, mas sobretudo em sua capacidade de sintetizar aspectos importantes da obra de Carver que se insinuam ou explicitam no processo.

Mais especificamente, o argumento a ser exposto diz respeito às diferentes relaçóes com a tradição literária implicadas nas opçôes estéticas que resultaram nas diferentes versões do livro. Trata-se então de entender como, ao realizar suas intervençóes, Gordon Lish situava os contos de Carver em um diálogo com a tradição característico das vanguardas artísticas europeias do século XX, marcado pelas noçôes de descontinuidade, estranhamento e ruptura e que, portanto, precisa presumir essa tradição para desconstruir seus hábitos consolidados. Daí a centralidade para a cultura de vanguarda de uma "consciência superior da história", tal como observado por Clement Greenberg (2013) em um ensaio sobre o tema. Em The Carver Chronotope, o livro de G. P. Lainsbury com o qual este artigo dialoga mais diretamente, os procedimentos narrativos de Carver são identificados com essa cultura vanguardista de modo geral, e com uma escola vanguardista específica. Como veremos, Lainsbury reitera a conhecida associação do autor ao Minimalismo, "uma sofisticada forma de escrita que leva em conta todas as lições do pós-modernismo" - e nesse sentido realiza um juízo crítico que, de acordo com as conclusóes dessa pesquisa, é perfeitamente adequado e pertinente no caso de Lish, mas só pode servir como eixo comparativo para a compreensão dos hábitos estéticos e literários de Raymond Carver (LAINSBURY, 2009, p. 12). 
Pois, nas opçóes do próprio Carver, identificamos a ausência de qualquer tradição com a qual o texto dialogue, na medida em que tudo se anuncia como um começo, como um início, em que não há qualquer anterioridade ou autoridade presumida, nem mesmo para ser desconstruída ou rejeitada. Não estamos no instante de uma "quebra entre o passado e o futuro" - como Hannah Arendt caracterizou a historicidade moderna -, mas sim diante daquilo que a própria pensadora alemá definiu como o initium dos recém-chegados, um fenômeno destituído de quaisquer referências para uma crítica histórica (ARENDT, 2003; ARENDT, 2005). Este mundo sem tradição, sem passado e sem referências para a ação é o mundo dos personagens de Carver, e não há como compreendê-los em sua perplexidade, confusão e arrebatamento sem a percepção dessas carências, associadas à carência de paradigmas estéticos como molduras reafirmadas ou rompidas pelos textos.

Nesse aspecto, cabe ressaltar desde já que o desdobramento da investigaçâao tampouco nos leva a ver Carver como o "iniciador" de uma nova escola literária ou tradição artística, ou uma espécie de pioneiro da estética que encontramos em seus relatos. Nada impede que isso aconteça ou venha a acontecer, mas o enfoque na construçáo de tal argumento nos colocaria diante de uma relaçáo com a tradição e com a história em que o paradigma moderno sequencial seria retomado, fazendo com que Carver surgisse no começo de uma narrativa a respeito de uma nova linhagem literária. O contraste a ser ressaltado aqui se dá entre a consciência de uma tradição literária com a qual se pode e se deve lidar, e que pode ser mobilizada como eixo de inovaçôes e rupturas estéticas (em Gordon Lish), e a ausência dessa dinâmica de continuidades e desconstruçôes como um componente central da dimensão interna da narrativa (em Raymond Carver).

De antemão, também, deve ser mencionado que Carver estabeleceu com outros autores do passado uma relação rica e interessante. Suas leituras de Anton Tchekhov e Franz Kafka, por exemplo, são reconhecidas como importantes eixos do debate crítico a respeito de sua obra. Porém, ele não estabeleceu uma relação conflitante com a tradição literária equivalente à realizada pelo modernismo, assim como o próprio Tchekhov jamais se diferenciou por aquela "consciência superior da história" característica das vanguardas europeias e também tão evidente em Tolstoi, por exemplo. Esse ponto é fundamental para explicar algumas afinidades entre Carver e Tchekhov; mas, de acordo com o enfoque comparativo desse artigo, ele será mobilizado mais frequentemente para tratar das diferenças entre Raymond Carver e Gordon Lish.

Serão mobilizadas nesta comparação as diferentes trajetórias profissionais de ambos, bem como aspectos dos ambientes culturais em que transitavam no momento da primeira ediçáo do livro, considerando-se as distinçôes entre a paisagem do Meio-Oeste estadunidense e o cenário artístico e intelectual de Nova Iorque no início dos anos 1980. Será também discutida a questáo da "formação" artística e intelectual de Carver, se é que podemos usar o termo para um autor tấo destituído de qualquer vínculo sistemático com uma linhagem literária. 
Porém, ao partirmos de elementos internos do texto, o contraste entre os títulos ganha certa proeminência. Pois são eles, os títulos, que sugerem de maneira mais imediata o horizonte de expectativas de leitura, e o campo de experiências implicado nos textos, indicando entáo de maneira sintética as variaçóes observadas nos procedimentos e decisôes do autor e do editor. ${ }^{1}$

Note-se então que "Iniciantes", o título escolhido por Carver para o conto que dá nome à obra, prevaleceu apenas na segunda versão publicada do livro (tanto para o conto quanto para a coletânea). Ele é menos impactante, menos convidativo e talvez menos inteligente que o título que viria a ser definido pelo editor. Mas traz uma sugestão, ainda que vaga num primeiro momento, de algo capaz de ganhar corpo e ressonância durante toda a leitura do livro, bem como em desdobramentos críticos posteriores, ao criar para a leitura um horizonte de expectativas baseado em um índice temporal singular. Podemos inclusive presumir que ele oferece pouco em termos de contextualização prévia do ato de leitura, mas este pouco, esta pobreza de informaçôes e de orientaçôes, pode muito bem ser uma característica intrínseca do ambiente em que circulamos ao adentrar o livro.

Comparativamente, temos What We Talk About When We Talk About Love, "Do que estamos falando quando falamos do amor". Este foi o título do conto e do livro homônimo que saiu pela Alfred Knopf em 1981. Em sua construção sintática (retirada do texto do conto), ele é sem dúvida inteligente; como decisão editorial, talvez tenha sido brilhante. Mas agora, de modo muito distinto do que no caso de um conto e um livro chamado "Iniciantes", estamos diante da promessa da revelação de um segredo, da desconstrução analítica de um discurso feito de camadas sobrepostas, da evidenciação de uma verdade oculta sob as aparências de falas convencionais. Ou seja, tudo aponta para um narrador iniciado nos enigmas, subterfúgios e sofisticaçóes de uma linguagem a ser decodificada. Até que ponto a versão de Lish consegue cumprir essa promessa - ou até que ponto ela precisaria cumpri-la - é algo a ser ainda discutido. De todo modo, para o leitor, o título sugere uma experiência de iniciação.

Assim, entre a literatura de iniciação proposta por Lish e a literatura dos iniciantes sugerida por Carver, surgem as diferenças cuja matizaçáo deve justificar o andamento desta proposta de leitura. Ela será feita em duas etapas. Na primeira, uma narrativa mais detalhada da relação Carver/Lish e dos trâmites que precederam a edição de 1981 fornecerá elementos para a compreensão das escolhas e valores em jogo no contraste entre ambos. Na segunda parte, de caráter interpretativo e comparativo, serão analisadas as diferenças nas versões de ambos para "Iniciantes" (o conto), em busca de elementos que se conectem a outros textos de Carver, servindo como índices da maneira singular como a questão da historicidade surge em sua obra.

\footnotetext{
${ }^{1}$ Para um esclarecimento sobre o uso das categorias "campo de experiência" e "horizonte de expectativa" na análise de textos de ficção, ver COMPAGNON, 2006, p. 209-213.
} 


\section{"Pelo amor de Deus, Gordon"}

Em "Fires", um ensaio de 1982, escrito para uma antologia da editora Harper \& Row, Raymond Carver elencou as principais influências em seu trabalho como escritor. No entanto, ele logo anuncia que se sente incapaz de definir com convicção suas "influências literárias" - e rapidamente passa a discorrer sobre estímulos de outra natureza, como as paisagens dos lugares onde morou. ${ }^{2}$ Cita também como "influência" decisiva o fato de ter se casado cedo e de ter iniciado sua carreira já com dois filhos pequenos em casa, mas nesse caso deixa claro que está falando de um constrangimento e de uma limitação. A esse respeito, vale observar que estímulos e constrangimentos nem sempre podem ser facilmente separados na trajetória de um artista, e, portanto, faz sentido reuni-los numa mesma categoria. A propósito de estímulos e constrangimentos: no final do ensaio, Carver menciona Gordon Lish (CARVER, 2009b, p. 734-745).

Eles se conheceram no final da década de 1960, na Califórnia. Carver estava então por volta dos vinte anos e havia publicado uns poucos contos e poemas em revistas literárias de circulaçáo restrita. Havia se mudado de cidade várias vezes com a família, sem sucesso tentara obter um diploma, e passara nesses intervalos por diversos empregos e subempregos temporários. Nascido em meio às paisagens desoladas do Noroeste dos EUA, por uma implausível conjunção de impulsos e conveniência chegou a fazer uma viagem a Israel, com uma bolsa do governo, em 1968, com a mulher, Maryann Burk, e os filhos. Mas a viagem - em que ele acreditou que recolheria o material para um ousado e sonhado romance de estreia - veio a integrar a lista de seus fracassos até aquele momento da vida. Assim, após o retorno, o filho de um pai alcoólatra (outra 'influência' importante, a quem Raymond Carver Jr. dedicou uma um ensaio isolado, "My father's life”) estava, ele mesmo, passando a beber cada vez mais.

Já Gordon Lish, naquele momento, estava prestes a receber o convite que seria a grande virada em sua carreira como editor. Enquanto permaneceu na Costa Oeste, ele e Carver tiveram uma amizade baseada em almoços, bebedeiras, discussóes sobre formas de se ganhar dinheiro com literatura e o projeto de uma revista literária a ser editada por ambos. Porém, logo após a publicação do primeiro número da Journal of American Fiction, Lish, através de uma carta audaciosa, conseguiu posto de editor de ficção na então já prestigiada revista Esquire. Mudou-se para Nova Iorque em seguida, ocupando um escritório na Madison Avenue.

Com isso, a maior parte da década de 1970, no que se refere à relação de ambos, pode ser resumida da seguinte maneira: enquanto Lish familiarizava-se com os expedientes, segredos, subterfúgios e macetes do mercado editorial nova-iorquino, adquirindo a reputação que o tornaria cada vez mais conhecido, respeitado e temido por aspirantes a uma carreira literária de todo o país (ganhando o apelido de "Captain Fiction" nos meios literários), Carver

\footnotetext{
${ }^{2}$ A respeito da relação dos textos de Carver com a geografia do Meio-Oeste estadunidense, ver ADELMAN, 2013.
} 
consolidava sua notoriedade como um bêbado desleixado, um profissional pouco confiável e um indivíduo falido nas outras tantas cidades onde morou no período. Foi, afinal, através de Lish que Carver conseguiu sua primeira publicação na Esquire, depois de ter dois contos rejeitados pela revista, através de cartas redigidas pelo próprio Lish em um tom direto e profissional ("Ele disse que estava devolvendo o conto. Ele não estava se desculpando por devolvê-lo, ele não estava devolvendo 'relutantemente', ele estava apenas devolvendo. Mas pediu para ver outros", Carver registrou) (CARVER, 2007). ${ }^{3}$

Sem contar com a condescendência do amigo, mas podendo confiar na avaliação crítica do editor, Carver teve ainda sua primeira coleção de contos, Would You Please Be Quiet, please?, de 1975, indicada para iniciar uma nova série da McGhraw-Hill Company. Volumes de histórias curtas passavam entâo a ser vistos como economicamente viáveis (ou mesmo lucrativos) por algumas editoras naqueles anos; e o livro de Carver, tendo alcançado boas vendas para um estreante, tampouco passou despercebido pela crítica. A Publishers Weekly, por exemplo, descreveu-o como uma reunião de " 22 minicontos que exploram o deprimente vazio da vida na América", mas com uma escrita perceptiva quanto "aos mundos inarticulados dos americanos" (apud SKLENICKA, 2009, p. 293). Todavia, nem o retorno financeiro nem o modesto reconhecimento crítico fez com que Carver interrompesse os ciclos que vinham dando ritmo à sua existência, com longos períodos de embriaguez e breves internaçóes em clínicas de reabilitação.

Mesmo com a publicação de Would You Please..., nenhuma transformação substantiva aconteceu na vida de Raymond Carver em meados da década de 1970, a não ser pelo agravamento de um quadro clínico já diagnosticado e da degradação pessoal e familiar em curso. Até que, em julho de 1977, ele parou de beber. É verdade que a decisão havia sido tomada várias vezes antes, mas dessa vez ele conseguiu sustentá-la. Num primeiro momento, foi preciso abandonar todos os esforços criativos e literários, que, com suas exigências de concentração e fôlego, além das inevitáveis frustrações diárias, poderiam levar à debilitação ou a uma recaída; num segundo momento, ele e Maryann se separaram. Mas, depois de conseguir evitar a ingestáo de álcool durante meses, Carver voltou a escrever; e, depois de ter conseguido evitá-la por um par de anos, passou a elaborar os contos que se tornariam o principal motivo dos debates em torno de seu segundo livro.

Ele reiteraria por diversas vezes a partir daí, até sua morte em 1988, como o período foi diferente e muito melhor do que tudo que vivera até então. Os temas da recuperação, da reconciliação e da alegria (em todas as suas fragilidades e riscos) são recorrentes em sua obra no período; mas desenvolver aqui esse ponto exigiria um tipo de análise que precisará ser deixada para uma próxima oportunidade. Considerando os propósitos deste estudo, basta afirmar que, em linhas gerais, os contos associados a esses temas e suas delicadas reviravol-

\footnotetext{
${ }^{3}$ Tradução do autor. No original: "He said he was returning the story. He was not apologizing that he was returning it, he was not returning it 'reluctantly', he was just returning it. But he asked to see others".
} 
tas, escritos no final dos anos 1970 e no começo da década seguinte, eram claramente mais extensos, mais “completos" (fuller foi o termo usado pelo próprio Carver) do que os anteriores. Sua escrita passou a sustentar construçóes narrativas de maior fôlego, com modulações estilísticas mais demoradas e oscilantes do que o verificado na brusquidão dos short-cuts que caracterizaram sua produção no primeiro livro. ${ }^{4}$

Assim, quando, em 1980, Carver reuniu um novo conjunto de ficçóes para enviar a Lish, havia entre elas textos de diferentes características e amplitudes, incluindo também alguns minicontos que repetiam procedimentos identificáveis à obra até então conhecida do escritor. Mas era nos textos mais recentes e mais extensos (os thirty-pagers ou forty-pagers, também nos termos de Carver, usados por ele com certo orgulho), que se encontrava a novidade da coletânea. Lish, naquele momento, havia deixado a Esquire e estava trabalhando na editora Alfred Knopf; em pouco tempo enviou a Carver uma resposta, confirmando seu interesse em publicar o livro. Logo Carver receberia também uma primeira versão editada, com poucas alteraçóes e pequenos cortes que não lhe alarmaram, sem que ele demonstrasse qualquer desconfiança em relaçáo à competência de Lish para aprimorar suas narrativas. Seguiu-se o adiantamento dos cinco mil dólares pela Alfred Knopf, vinculado à assinatura do contrato de publicação.

E ele não tinha, de fato, nenhum motivo para duvidar de que o encaminhamento lhe renderia os melhores resultados, tanto financeiros quanto artísticos. Em uma carta deste período ao editor, enquanto eram feitas as primeiras negociaçóes, declarou que, desde que passara a lhe enviar notícias e instruções “do Grande Mundo [of the Great World]”, Lish havia se tornado seu "herói" - e disse-lhe também que não deixasse de fazer todas as mudanças que acreditasse favoráveis para os contos (CARVER, 2007). Tampouco havia, entre ambos, precedentes de desentendimentos mais sérios que justificassem uma preocupação com o destino do livro. Daí a surpresa e o desespero de Carver ao receber uma segunda versão dos manuscritos editados, com cortes e alteraçóes de impacto muito maior que os aprovados antes da assinatura do contrato.

Cerca de $40 \%$ do texto foi suprimido em algumas narrativas, e há contos que tiveram quase metade de suas palavras rejeitadas na edição de 1981. Esta foi a razão mais óbvia do assombro de Carver ao verificar o manuscrito editado, mas haveria outras, como a questão dos títulos e dos detalhes de algumas passagens, que ele tentaria discutir na carta redigida imediatamente após a leitura. No entanto, nem estes detalhes nem a questão mais evidente envolvendo os cortes seriam objetos de uma negociação. O livro foi publicado na versão definida por Gordon Lish, e já em maio de 1981 alcançou a marca de 15.000 cópias vendidas, o que levou a Vintage Editorial a comprar por 20.000 dólares os direitos para a edição em paperback (SKLENICKA, 2009, p. 367).

\footnotetext{
${ }^{4}$ Short-Cuts (1993) foi o título escolhido para o filme do diretor Robert Altman inspirado em contos de Carver editados por Gordon Lish.
} 
What We Talk About When We Talk About Love veio então a ser conhecido e bem recebido pelo público. As vendas melhoraram a condição financeira do escritor, e o reconhecimento lhe proporcionou convites para atuar como professor de escrita criativa em universidades. Nem por isso o relacionamento com Lish deixou de ser afetado pelo breve confronto a respeito da obra. Em 1983, Carver publicaria Cathedral, outra coletânea de contos, solicitando e conseguindo que a interferência do editor estivesse voltada sobretudo para decisóes quanto à arte de capa e no arranjo dos contos. A esta altura restava pouco da amizade de ambos, e Lish não estaria envolvido nas publicaçóes posteriores de Carver.

Entre estas, destaca-se Where I'm Calling From, de 1987. Trata-se de uma coleção em que figuravam contos inéditos, de construção rítmica cuidadosa, e contos curtos antigos, do início da carreira de Carver. O editor da seleção, Gary Fisketjon, chegou inclusive a afirmar que optou pela mistura de contos da década de 1970 com textos recentes para mostrar como o trabalho de Carver havia evoluído consistentemente no período, e para "dispensar o rótulo idiota de 'minimalista"' (SKLENICKA, 2009, p. 458). No contraste com as primeiras publicaçóes e com os contos editados por Lish, então, sobressaem contos que requerem um tempo e espaço mais dilatados para seus desdobramentos.

Tanto Cathedral quanto Where I'm Calling From obtiveram também bons números de venda, mas é possível atribui-los em parte ao fato de Carver ter saído do ostracismo por intermédio da conflituosa parceria com Lish. De modo que a discussão sobre os motivos do sucesso comercial deste ou daquele livro é infrutífera. O certo é que, uma vez conquistada maior segurança quanto à pertinência de suas criaçôes, o escritor optou pela divulgação de seus contos em versóes imunes à interferência editorial de Lish, passando a trabalhar com profissionais com quem demonstrou maior afinidade estética. Talvez a conquista de certa estabilidade emocional, após um período mais extenso de abstinência do álcool, tenha também contribuído para que ele sentisse maior confiança no resultado de seus esforços criativos. Uma estabilidade e uma abstinência que ele afirmou estarem ameaçadas na carta de julho de 1980 a Gordon Lish.

"Como te disse, eu estou confuso, exausto, paranoico, e com medo, sim, com medo das consequências para mim deste livro sair da forma como está", ele escreveu no último parágrafo da carta (CARVER, 2009a, p. 996).5 Quanto às "consequências", provavelmente estava se referindo a uma eventual recaída, que felizmente não aconteceu. Mas nada leva a crer que estivesse blefando ou fazendo uma chantagem emocional. $\mathrm{O}$ trecho final surge naturalmente, ainda que de maneira impactante, como a conclusáo de uma série de apelos pessoais em que elementos de caráter estético na discussão do texto cumprem um papel reduzido. Carver até mesmo insiste em colocar-se em uma posiçáo subalterna a esse respeito; pede desculpas repetidas vezes pela "decepçáo" de que estaria sendo motivo; e somente em

\footnotetext{
${ }^{5}$ Tradução do autor. No original: "As I say, I'm confused, tired, paranoid, and afraid, yes, of the consequences for me if the collection came out in its present form".
} 
um pós-escrito sintético assume sua principal requisição, a de que a preparação do livro fosse interrompida naquele exato momento.

Há, nos argumentos de Carver, portanto, um elemento sentimental cuja centralidade merece ser explorada. Até porque a detecção de certo sentimentalismo nas narrativas que sofreram maiores cortes foi apontada por Lish e por críticos posteriores como motivo suficiente para a intervenção do editor. Fragmentá-las e estabelecer cortes abruptos entre suas cenas, eliminando a fluência narrativa, implicava assim o convite a uma leitura mais intelectualizada, em que a suspensão de descrença dava lugar ao distanciamento e ao interesse quanto aos métodos narrativos empregados. Do mesmo modo, a subtração dos finais em que algum tipo de conclusão era sugerido (ainda que de maneira sutil e evasiva) implicava uma dose maior de estranhamento por parte do leitor, no lugar do envolvimento emocional com o desenlace da trama.

Em resumo, Lish atuava a partir daquele ponto de vista - e daquele regime de historicidade - em que a arte "exibe e exaure seus recursos", para usar uma expressão de Jorge Luis Borges (2005, p. 305). Trata-se de um momento de desconfiança diante de convençóes formais e esgotamento de hábitos artísticos tradicionais, como o que se verificou na Europa letrada no início do século XX. Decerto, a própria noção de estranhamento e a de evolução literária, propostas por formalistas como Chklovski e Tynianov no mesmo período, oferece ao fenômeno um caráter renovador que muito beneficiou a avaliação crítica do modernismo europeu (TYNIANOV, 2002, p. 473-486; CHKLOVSKI, 1971, p. 39-56). Assim, ao adequar a prosa de Carver às expectativas do instruído e intelectualizado público leitor nova-iorquino dos anos 1980, é possível que Lish estivesse adequando-a mais amplamente a um sentimento histórico de esgotamento das formas tradicionais e necessidade de renovação dos trâmites da narrativa moderna, que, a partir de sua manifestação no velho mundo, reverberava nos leitores das editoras americanas mais conceituadas e cosmopolitas do período.

No entanto, nada mais distante das narrativas então elaboradas por Carver do que o propósito do choque e do desconcerto em relação a convençôes culturalmente estabelecidas. Em primeiro lugar, porque isso presumiria uma familiaridade com tais convençóes e um lastro na tradição literária dos quais ele estava destituído; em segundo, porque o desconcerto e a perplexidade são antes características de seus personagens do que efeitos da leitura de seus textos. Não que uma coisa exclua a outra, naturalmente: de protagonistas desorientados faz-se um leitor igualmente perdido. Mas era através da empatia e do envolvimento emocional, e náo do distanciamento e do estranhamento formalista, que Carver buscava criar uma relação de cumplicidade com o leitor, construindo com cuidado as conexóes e desdobramentos que Lish consideraria supérfluos.

Os "mundos inarticulados" de uma experiência histórica marcada pela pobreza, pela destituição e pela insegurança encontraram em Carver certo grau de articulação, ainda que precária, frágil, hesitante. Lish, por sua vez, empreendeu a desconstrução de um discurso 
que mal havia começado a se articular: o discurso de um iniciante. O problema verificado entre sua atuação como editor (diante das qualidades que depois viriam a ser observadas nos textos) situa-se nesse descompasso, e não em uma valoração a priori da autoridade do autor sobre a própria obra. Trata-se então de avaliar como essa dissonância se expôs nas diferentes versóes de um conto, e de que maneira o universo de Carver, uma vez respeitadas suas potencialidades dramáticas, ampliou-se em textos subsequentes.

\section{Viver pela primeira vez}

Para a epígrafe da coletânea Where I'm Calling From, que reuniu contos de momentos diversos de sua carreira em 1987, Carver escolheu a seguinte passagem de Milan Kundera: "Nunca temos como saber o que querer, porque, ao vivermos uma só vida, não podemos nem compará-la com vidas anteriores, nem aperfeiçoá-la em vidas por vir" (apud CARVER, 1988, p. XIII). ${ }^{6}$ O trecho ecoava outra epígrafe, presente em um dos livros de poesia de Carver, por sua vez extraída de um poema de Lou Lipsitz: "Agora à outra vida. A que será sem erros [Now for the other life. The one without mistakes]" (apud CARVER, 1996, p. 38). A recorrência do tema pode estar relacionada ao título escolhido pelo tradutor Cide Piquet para a coletânea de poemas de Carver publicada no Brasil em 2017: Esta vida.

Note-se como, seja através da constatação de Kundera, seja através da ironia de Lipsitz, o caráter singular e inédito de uma vida - "esta vida" - fica ressaltado. Presume-se que até seria possível aprender com a experiência - em vidas futuras, na "outra vida" - mas isto só enfatiza o fato de que, nesta, não há experiência passada da qual possamos retirar ensinamentos. Náo é que o sujeito esteja apartado de uma herança por força de uma ruptura; simplesmente, não há herança alguma. Tudo está sempre no começo, cada vida é um início, uma aurora repleta de possibilidades, incluindo aí os mais mesquinhos, estúpidos e precipitados erros que se possa imaginar.

"Se eu pudesse voltar em uma outra vida, uma época diferente e tudo, sabe de uma coisa? Eu ia querer voltar como um cavaleiro. Você ficava era bem seguro usando aquela armadura toda", diz um personagem de "Beginners", o conto que seria publicado em sua versão integral - não editada por Gordon Lish - pela Library of America em 2008. No mesmo volume, encontra-se What We Talk About When We Talk About Love, o livro, e "What we talk about when we talk about love", o conto - de modo que a edição torna possível comparar as duas versóes com alguma praticidade. $\mathrm{O}$ trecho citado encontra-se repetido em ambas, sem alteraçôes. No entanto, as diferenças ficam evidentes já ao percebermos que, na versão de 1981, o conto ocupa 13 páginas (310-322), enquanto na outra são 22 (927-948).

\footnotetext{
${ }^{6}$ Tradução do autor. No original: "We can never know what to want, because, living only one life, we can neither compare it with our previous lives nor perfect it in our lives to come".
} 
Foge ao propósito desta análise um cotejamento minucioso das diferenças entre ambos os textos, porque os detalhes são muitos. Mas cabe assinalar alguns pontos. Em primeiro lugar, além da alteração no título, percebemos que na versão de Lish também o nome do personagem que gostaria de viver como um cavaleiro medieval foi trocado, de Herb para Mel. Sua apresentação ao leitor consta como a frase do narrador para iniciar o texto: "Meu amigo Mel McGinnis estava falando. Mel McGinnis é um cardiologista, e isso às vezes dá a ele o direito". Já na versão de Carver as primeiras frases são as seguintes: "Meu amigo Herb McGinnis, um cardiologista, estava falando. Nós quatro estávamos sentados ao redor da mesa da sua cozinha bebendo gim”. A partir daí, procede-se a uma ambientação da cena bem mais extensa do que a preservada na edição de 1981.

A situação é simples, prosaica: dois casais bebendo e conversando sobre o amor. $\mathrm{O}$ conto não vai muito além disso, mesmo na versão de Carver, embora nela haja mais movimento na parte final, quando Herb, bêbado, sai para tomar uma ducha, deixando sua mulher Terri chorando e falando a seu respeito com os outros personagens, Nick e Laurie (essa passagem foi subtraída por Lish quase inteiramente). Nesse ponto, o narrador de Carver retorna à questão da ambientação e da luz repetidamente, ressaltando a lenta chegada do crepúsculo, fundamental para o desfecho da narrativa no limiar da noite. Enquanto, na versão de Lish, ela é anunciada em um arremate tão mais abrupto quanto o início: "Eu podia ouvir meu coração batendo. Eu podia ouvir o coraçáo de todos. Eu podia ouvir o barulho humano que nós fazíamos lá sentados, nenhum de nós se movendo, nem mesmo quando o quarto ficou escuro”.

Isto é o suficiente para percebermos a principal diferença entre as duas propostas. Em um caso, sobressai a elaboração ritmicamente cadenciada de um diálogo com matizes que se espelham no jogo de luzes e sombras do decorrer da tarde, embora ele não esteja destituído da ameaça de rupturas e da menção ao trágico; no outro, temos um texto que, a partir da breve descrição de uma cena cotidiana, se move muito mais rapidamente na exposição de desentendimentos e conflitos, terminando de repente, logo que suficientemente revelado o desespero a princípio oculto na banalidade da conversa.

Este último procedimento, de fato, está bastante de acordo com o dos primeiros contos de Carver, aqueles que lhe deram algum reconhecimento aos vinte e poucos anos, e compreende-se o esforço de Lish em adequar o conto para repetir o sucesso e atender a expectativas do público. No entanto, quando se compara o texto integral com os demais contos que Carver escreveu depois dos trinta, ele é até menos desenvolvido em sua trama do que outros "fourty-pagers", ainda mais meticulosos e com arcos temporais bem mais amplos, mesmo considerando que certa economia de recursos estilísticos não deixou de ser uma marca de sua escrita.

Resta observar, então, em que medida as mudanças efetuadas nesta narrativa em particular exibem duas concepções tão díspares do potencial do livro, tão opostas em seus vetores e fundamentos, que foi impossível conciliá-las em um resultado satisfatório para autor e editor. Isto 
diz respeito tanto às passagens que Lish optou por suprimir quanto àquelas que manteve com modificações substanciais. Isto também diz respeito, é claro, ao título do conto e à maneira como ele estabelece expectativas para a narrativa em cada experiência de leitura.

Reforçando então um ponto já mencionado: com "Beginners", estamos diante de um indício da condição dos personagens em suas relaçóes com o tempo e com a experiência. Com "What we talk about when we talk about love", estamos diante da promessa de revelação de um segredo oculto nas camadas mais profundas do discurso. No primeiro caso, entende-se que o aspecto prosaico das falas e dos personagens decorre daquela condição, incluindo aí seus erros, precipitaçóes e perplexidades; no segundo, presume-se que sob as superfícies contingentes do prosaísmo existe uma "segunda história", uma história escondida, como aquela que Ricardo Piglia (2000, p. 87-94) atribui à estrutura clássica do conto, ao afirmar que "o conto é um relato que encerra um relato secreto".

Não se trata, aqui, de imaginar que Lish tenha adequado o trabalho de Carver às convençóes do gênero, mas sim de que ele estabeleceu um diálogo com essas convençóes e suas possibilidades, tal como era frequente no modernismo europeu, ao insinuar a existência da história secreta que de maneira alguma se evidencia no final. Fica assim a sensação de que "algo além" do que foi exposto está em jogo na trama, mas o desvelamento do mistério permanece em aberto no final abrupto que se propóe. Nesse ponto, há um trecho em particular que merece ser mencionado, não obstante a mudança de apenas uma palavra.

Ele está situado em um momento de suspensão dos debates e conflitos que marcam o transcurso da tarde, e que assinala o fim da primeira parte do conto (aquela que foi preservada em sua maior parte por Lish). A esta altura, já está claro o contraste que atravessará a narrativa até o fim: Herb/Mel e Terri, o casal anfitrião, está vivendo uma crise que vai se revelando através das diferentes concepçôes do amor por eles enunciadas, enquanto Nick e Laurie, o narrador e sua mulher, estão ainda no início de um relacionamento. Eles então dizem estar felizes e apaixonados - o que leva Terri a comentar que "ainda estão em lua-de-mel, esperem só pra ver" -, mas a declaração de ambos não deixa de ser modesta e sincera, o que leva Herb/Mel a propor um "brinde ao amor verdadeiro".

$\mathrm{O}$ brinde acontece, e aproveitando o silêncio subsequente surgem referências do narrador a latidos de cães lá fora e à luz do sol da tarde como uma presença no ambiente. Em "Beginners", a versão de Carver, essa passagem termina da seguinte maneira: "Erguemos nossos copos novamente e sorrimos uns para os outros como crianças que tivessem concordado sobre algo de uma vez por todas" (CARVER, 2009c, p. 932). J Já em "What we talk about...", lê-se: "Erguemos nossos copos novamente e sorrimos uns para os outros como crianças que tivessem concordado sobre algo proibido" (CARVER, 2009d, p. 314). ${ }^{8}$

\footnotetext{
${ }^{7}$ Tradução do autor. No original: "We raised our glasses again and grinned at each other like children who had agreed on something for once".

${ }^{8}$ Tradução do autor. No original: "We raised our glasses again and grinned at each other like children who had agreed on something forbidden".
} 
Não é o caso de sobrecarregar de intencionalidade as mudanças nas diferentes versóes. Mas, neste caso, as duas frases não apenas oferecem sinais para uma comparação analítica, como também compóem uma síntese imagética da partitura de cada texto, considerando-se a mudança de perspectiva de cada título. Em "Beginners", estamos diante de personagens que, como crianças, de repente criam uma espécie de cumplicidade tácita a partir do ritual do brinde, concordando em silêncio a respeito de um assunto para o qual as palavras parecem ser motivo de maior confusão e desespero; em "What we talk about...", a menção ao proibido reitera a ideia de que essa cumplicidade é de outra natureza, de que há um interdito no emaranhado das falas, de que no silêncio reside algo mais do que a simples ausência de palavras.

Já os trechos mais longos que Lish optou por excluir de "What we talk about...", reduzindo-o a quase a metade da extensão de "Beginners", fazem sobretudo com que o ritmo narrativo seja bastante distinto em ambas versóes, favorecendo diferentes tipos de envolvimento e experiências de leitura. Porém há dois componentes do conteúdo dessas passagens que requerem uma menção. Um deles está na conversa corriqueira dos personagens sobre o lugar para onde iriam em seguida, para prosseguir noite adentro com as bebidas e os diálogos. Terri sugere um restaurante recém-inaugurado na cidade, chamado The Library, que ela, no entanto, apresenta com algum estranhamento: "Eles têm estantes de livros mesmo lá, com livros de verdade nelas".

Além de cumprir um papel nas oscilações rítmicas do texto, proporcionando a princípio uma significativa distensão narrativa, o trecho serve também à caracterização dos personagens, sobretudo de Herb ("Eu não sou instruído. Eu só aprendi o que tinha que aprender. Sou um cirurgião e tal, mas na verdade sou só um mecânico. Eu vou lá e conserto as coisas que dão defeito no corpo das pessoas. Sou só um mecânico", ele diz ao final desta passagem). E isso nos ajuda a entender porque um outro corte efetuado por Lish, de ainda maior extensão, tem um efeito decisivo nas diferentes leituras. Pois será justamente Herb o responsável pelo discurso mais longo do conto, de uma amplitude inclusive rara em toda a obra de Carver. Em "What we talk about...", ele ocupa dois parágrafos breves. Em "Beginners", após o mesmo parágrafo inicial, ele é retomado após os quatro decidirem ir ao The Library à noite, e a fala prossegue ininterruptamente por cerca de quatro páginas.

Em ambos os casos, tudo começa com a menção de Mel/Herb a um casal de idosos que teria conhecido no hospital em que trabalha. Em ambos os casos, a introdução do tema é significativa: é nela que surge a frase segundo a qual deveríamos sentir vergonha por achar que sabemos do que estamos falando quando falamos do amor. Mas, na versão publicada em 1981, as expectativas criadas pelo título conferem maior peso à afirmativa e ao que ela anuncia, isto é, à promessa de que algo mais profundo ou verdadeiro a respeito do amor será revelado. Então Mel prossegue relatando a história do idoso que, depois de ter sofrido um acidente de automóvel junto à mulher, passou seus dias no hospital deprimido e transtornado, não por causa de suas fraturas, escoriaçôes e traumas, mas simplesmente porque naqueles dias ele ficou impedido de ver a esposa. 
A brevidade dessa paráfrase não faz justiça mesmo ao texto preservado por Lish, mas não deixa de ser o suficiente para expor seu conteúdo. Ou seja, aqui a história do casal de idosos serve para que Mel exponha sua visão do amor absoluto, ideal, perene, antes que as conversas retomem um aspecto mais banalizado e o conto termine abruptamente. Já em "Beginners", a continuação posterior do discurso inicial de Herb faz com que ele vá bastante além da enunciaçáo de um ideal abstrato, ao mesmo tempo em que, ao ganhar corpo e forma, o relato adquire uma concretude imagética de certo modo aquém da idealização por ele proposta inicialmente. Assim, nas páginas em que ficamos sabendo em detalhes a história de Henry e Anna Gates, eles se tornam personagens do conto também, e náo apenas instrumentos para o andamento da trama. Eles chegam inclusive a configurar uma narrativa à parte, excluída por Lish.

Tudo surge da voz embriagada de Herb, e até certo ponto segue servindo à caracterização de sua visão idealizada do amor, em contraste com a realidade presente de seu relacionamento com Terri. Mas o próprio fato de ser ele quem consegue reter a atenção de ouvintes e leitores por tanto tempo, com uma narrativa bêbada, porém bem encadeada e comovente, é importante na composição de "Beginners". Nesse caso podemos de fato dizer que Carver estabelece um diálogo (provavelmente involuntário) com uma tradição literária intermitente: aquela em que um personagem patético, desesperado ou bestial nos surpreende com um discurso longo e emocionante, para depois submergir de novo em sua confusão inarticulada. O fenômeno é recorrente em Shakespeare (em geral nas peças cômicas), reaparece em Tchekhov (no final de $A$ gaivota, por exemplo), e foi explorado por Jorge Luis Borges em um breve ensaio sobre temas correlatos (BORGES, 2006, p. 136-139).

Por outro lado, se nos ativermos somente à linhagem dos oradores embriagados, a referência mais imediata é justamente ao texto antigo com que "Beginners" estabelece uma conexão mais evidente: o Banquete de Platão. Tampouco nesse caso podemos inferir a existência de um diálogo voluntário de Carver com a tradição filosófica ocidental; no entanto, a estruturação do conto como um colóquio a respeito do amor torna a lembrança inevitável. Além disso a comparação é capaz de reforçar o diagnóstico de que não há iniciação alguma, mas apenas um início, na ficção do autor norte-americano. Nesse sentido, devemos recorrer brevemente à análise do diálogo platônico feita por Martha Nussbaum em $A$ fragilidade da bondade (2009), e à ênfase que a filósofa confere justamente à irrupção no texto da fala ébria de Alcibíades, contraposta ao discurso de Sócrates.

Em linhas gerais, segundo Nussbaum, temos, de um lado, uma concepção do amor atribuída por Sócrates aos ensinamentos de uma sacerdotisa chamada Diotima, expostos por ele como o desvelamento de um mistério e uma "revelaçáo para o iniciado". Seguindo uma série de passos em direção a uma experiência amorosa cada vez mais elevada, dissociada do corpo, autossuficiente, dá-se a ascese que ele propóe aos ouvintes. Porém, após o belo e convincente discurso socrático, Alcebíades irrompe bêbado na festa, e contrapóe à universalidade abstrata do ponto de chegada de Diotima seu ponto de partida prático, particular e corporal: isto 
é, sua própria paixão por Sócrates. Ainda de acordo com Nussbaum, a aparição súbita e violenta consegue transtornar o efeito das palavras de Sócrates: "Posso seguir Sócrates somente se, como Sócrates, estou persuadido da verdade da consideração de Diotima; e Alcibíades me rouba esta convicção", afirma a filósofa (NUSSBAUM, 2009, p. 174).

No Banquete, portanto, a verdade universal alcançada pelo iniciado é desconstruída pela verdade parcial do iniciante. Já em "Beginners", o discurso de Herb é o que mais se aproxima da fala socrática, na medida em que ele comunica um ideal de experiência amorosa que teria aprendido com Henry e Anna Gates - porém esse ideal permanece inalcançável para ele mesmo em sua angústia e embriaguez, de modo que surge como uma projeção inserida no diálogo entre iguais, e fora do alcance de todos eles. Não há ninguém no texto capaz de assumir uma posição pedagógica; aquele que mais se aproxima desse lugar é também o mais patético e desesperado dos personagens; e logo ele se vê de volta à sua habitual confusão inarticulada. Desse modo, tampouco há um discurso a ser desconstruído no decorrer do conto, mas apenas tentativas de construção de algo a partir de bases frágeis, instáveis e carentes de experiência histórica.

Em suma, no contraste com o diálogo platônico fica ainda mais evidente que não há iniciados na obra de Carver; há apenas iniciantes. Gordon Lish, por sua vez, operou cortes na narrativa que causam um efeito de estranhamento e ao mesmo tempo favorecem a alusão a um segredo jamais revelado e talvez esquecido. O procedimento aproxima "What we talk about...” dos contos de Franz Kafka, que, segundo Walter Benjamin (2012, p. 147-178), constituem um corpus de notas de pé-de-página referentes a um texto antigo não mais disponível, expondo o rompimento do indivíduo europeu moderno com sua herança cultural. Trata-se de um diálogo com a tradição em que a tradição é silenciada pela ruptura entre o passado e o futuro, e a herança histórica torna-se presente sob a forma de uma ausência, algo que não está mais lá, embora se presuma que tenha existido e tenha feito sentido para os que nela iniciaram-se antes de nós. A questão é que, na proposta de Carver, não há exatamente um “antes”, nem mesmo como ausência. Nela, tudo está no começo.

\section{Considerações finais}

Uma vida, esta vida, a primeira vida: é com o que se deparam os personagens de Raymond Carver em seus contos. Apenas iniciantes, portanto, que não encontraram neste mundo os iniciados capazes de lhes entregar as chaves do conhecimento e transmitir-lhes experiências úteis, nem mesmo aquelas que se cristalizaram através da repetição, com as quais precisariam romper para seguir adiante. Eles não têm ancestrais, e tudo está no começo; tampouco há antigos segredos que tenham sido soterrados pelos séculos e pelas sucessivas geraçóes.

Em uma entrevista pouco antes de sua morte, Carver afirmou: 
Sou uma dessas pessoas confusas, atordoadas, venho desse mundo, essas são as pessoas com quem trabalhei e ganhei a vida por muitos anos. É por isso que nunca tive o menor interesse em escrever um conto ou poema que tenha a ver com a vida acadêmica, com professores ou alunos e tal. Simplesmente não me interessa tanto. As coisas que deixaram uma impressão indelével em mim foram as coisas que vi em vidas que testemunhei serem vividas ao meu redor, e que vivi na minha própria vida. São vidas de pessoas que realmente tinham medo quando alguém batia em sua porta, de dia ou de noite, ou quando o telefone tocava; elas náo sabiam como iriam pagar o aluguel ou o que fazer se a geladeira pifasse (CARVER apud MCCAFERRY e GREGORY, 1987, p. 78-79). ${ }^{\text {? }}$

Estes são os personagens de Carver, gente que não sabe o que fazer: e o que vale para uma geladeira pifada, vale também para sua experiência afetiva. A pobreza de quem não recebeu nenhuma herança em dinheiro, e precisa encontrar um jeito de se virar, é também a de quem não recebeu um legado de conhecimentos e preceitos morais, mas ainda assim precisa encontrar um jeito de agir. São pessoas que não sabem o que fazer quanto ao amor, nem quando se apaixonam, nem quando um relacionamento entra em crise, nem quando precisam se recuperar de uma separação, mas vão tateando nesse mundo sem referências em busca de algum suporte para suas decisóes. Assim, tampouco deixam um rastro de ensinamentos, segredos ou vilezas a serem desvelados pelo olhar hermenêutico do crítico diante da obra literária. De modo que, no final das contas, não há mistério algum em que seus leitores sejam iniciados, ou em que precisem iniciar-se para a leitura. Basta que se sintam eles próprios iniciantes neste mundo, para que saibam do que estamos falando quando falamos de Raymond Carver.

\section{Referências}

ADELMAN, Bob. Carver Country: the world of Raymond Carver. New York: Quantuck Lane Press, 2013.

ARENDT, Hannah. A condição humana. Trad. Roberto Raposo. Rio de Janeiro: Forense Universitária, 2003.

ARENDT, Hannah. Entre o passado e o futuro. Trad. Mauro Barbosa. São Paulo: Perspectiva, 2005.

\footnotetext{
9 Tradução do autor. No original: "I am one of those confused, befuddled people, I come from people like that, those are the people I've worked with and earned my living beside for years. That's why I never had any interest whatsoever in writing in a story that has anything to do with academic life, with teachers or students or so forth. I'm not that interested. The things that have made an indelible impression on me are the things I saw in lives I witnessed being lived around me, and in the life I lived myself. These were lives where people really where scared when someone knocked on their door, day or night, or when the telephone rang; they didn't know how they were going to pay the rent or what they could do if the refrigerator went out".
} 
BENJAMIN, Walter. Franz Kafka: a propósito do décimo aniversário de sua morte [1934]. In: BENJAMIN, Walter. Magia e técnica, arte e politica: ensaios sobre literatura e história da cultura. Trad. Sérgio Paulo Rouanet. São Paulo: Brasiliense, 2012. p. 147-178

BORGES, Jorge Luis. Historia universal de la infamia [Prólogo a la edición de 1954] In: BORGES, Jorge Luis. Obras completas, v. 1. Buenos Aires: Emecé Editores, 2005. p. 303-372. BORGES, Jorge Luis. Historia de los ecos de un nombre [1955]. In: BORGES, Jorge Luis. Obras completas, v. 2. Buenos Aires: Emecé Editores, 2006. p. 136-139.

CARVER, Raymond. All of Us: the collected poems. New York: Vintage, 1996.

CARVER, Raymond. Letter to Gordon Lish [08.07.1980]. In: CARVER, Raymond. Collected Stories. New York: Library of America, 2009a. p. 992-996

CARVER, Raymond. Fires. In: CARVER, Raymond. Collected Stories. New York: Library of America, 2009b. p. 734-745

CARVER, Raymond. Beginners. In: CARVER, Raymond. Collected Stories. New York: Library of America, 2009c. p. 749-956.

CARVER, Raymond. What we talk about when we talk about love. In: CARVER, Raymond. Collected Stories. New York: Library of America, 2009d. p. 221-328.

CARVER, Raymond. Iniciantes. Trad. Rubens Figueiredo. São Paulo: Companhia das Letras, 2009e.

CARVER, Raymond. Letters to an Editor: letters from Raymond Carver to Gordon Lish. The New Yorker, December 24, 2007 Issue. Disponível em: <https://www.newyorker. com/ magazine/2007/12/24/letters-to-an-editor>. Acesso em: 15 jan. 2018.

CARVER, Raymond. Where I'm Calling From: new and selected stories. New York: The Atlantic Monthly Press, 1988.

CHKLOVSKI, Victor. A arte como procedimento. In: TOLEDO, Dionísio de (org.). Teoria da literatura: formalistas russos. Porto Alegre: Globo, 1973.

COMPAGNON, Antoine. O demônio da teoria: literatura e senso comum. Trad. Cleonice Mourão e Consuelo Santiago. Belo Horizonte: Editora da UFMG, 2006.

GREENBERG, Clement. Vanguarda e kitsch. In: GREENBERG, Clement. Arte e cultura: ensaios críticos. Trad. Otacílio Nunes. São Paulo: Cosac \& Naify, 2013.

LAINSBURY, G. P. The Carver Chronotope: contextualizing Raymond Carver. New York: Routledge, 2009.

MCCAFERRY, Gregor; GREGORY, Sinda (eds.). Alive and Writing: interviews with American authors of the 1980s. Chicago: University of Illinois Press, 1987.

NUSSBAUM, Martha. A fala de Alcibíades: uma leitura de O Banquete. In: NUSSBAUM, Martha. A fragilidade da bondade: fortuna e ética na tragédia e na filosofia grega. Trad. Ana Aguiar Cotrim. São Paulo: Martins Fontes, 2009. 
PIGLIA, Ricardo. Teses sobre o conto. In: PIGLIA, Ricardo. Formas breves. Trad. José Marcos Mariani de Macedo. São Paulo: Companhia das Letras, 2000.

SKLENICKA, Carol. Raymond Carver: a writer’s life. New York: Simon \& Schuster, 2009. TYNIANOV, Iuri. O ritmo como fator construtivo do verso [extraído de O Problema da Linguagem Poética, 1924]. Trad. Luiza Lobo. In: LIMA, L. C. (org.) Teoria da literatura em suas fontes, vol. 1. 3. ed. Rio de Janeiro: Civilizaçâo Brasileira, 2002. 